\title{
The exercise paradox may be solved by measuring the overall thrombotic state using native blood
}

\author{
Hideo Ikarugi, ${ }^{1, *}$, Junichiro Yamamoto ${ }^{2}$ \\ ${ }^{1}$ School of Economics, University of Hyogo, Kobe, Japan; \\ ${ }^{2}$ Kobe Gakuin University, Kobe, Japan.
}

\begin{abstract}
Summary While exercise is widely believed to prevent atherothrombotic diseases, it occasionally causes sudden death. This exercise paradox may be due to the inadequate testing of the thrombotic and thrombolytic status. A recently developed shear-induced thrombosis/ endogenous fibrinolysis test performed with non-anticoagulated blood samples allows the assessment of the thrombotic state of an individual both at rest and after exercise. This sensitive and physiologically relevant test may help to solve the aforementioned exercise paradox.
\end{abstract}

Keywords: Exercise, platelet reactivity, platelet aggregation, coagulation, fibrinolysis, nonanticoagulated blood

\section{Introduction}

Prevention of atherothrombotic diseases such as coronary artery disease and stroke is an important social issue. Evidence from epidemiological and clinical studies suggests that regular exercise is an efficient way to prevent such diseases. However, the benefit of exercise is still a subject of debate that is referred to as the "exercise paradox" or the "double-edged sword in exercise" (1-5).

Findings from studies that have sought to explain that paradox are a subject of debate (6-10). The intensity of exercise of endurance training may be responsible for this paradox according to the American College of Sports Medicine (Table 1) (11). Inconsistent evidence might be partly due to differences between the laboratory tests used to study the thrombotic status. Hemostasis tests in common use are performed on anticoagulated blood (12-14). Anticoagulants interfere with the mechanism of hemostasis and render the obtained results unphysiological. To overcome

Released online in J-STAGE as advance publication February 14, 2017.

*Address correspondence to:

Dr. Hideo Ikarugi, School of Economics, University of Hyogo, 8-2-1, Gakuen-nishimachi, Nishi-ku, Kobe, Hyogo 651-2197, Japan.

E-mail: ikarugi@econ.u-hyogo.ac.jp this limitation, some tests (shear-induced plateletrich thrombosis and thrombolysis tests) use nonanticoagulated whole blood (15-20). The aim of the present review was to compare the effects of short-term and long-term exercise on the thrombotic state. These effects were measured with two types of tests using either anticoagulated or non-anticoagulated blood in order to understand the exercise paradox.

2. Measurement of the effects of acute and long-term exercise on the thrombotic/fibrinolytic state using anticoagulated blood

\subsection{Effect of acute exercise on platelet function}

Only a few studies have examined the effect of low-intensity exercise $(<49 \%$ maximal oxygen consumption, $\% \dot{\mathrm{V}} \mathrm{2}_{2_{\max }}$ ) on platelet reactivity. However, the effect of moderate-intensity exercise $(50-74 \%$ $\dot{\mathrm{V}} \mathrm{O}_{2_{\max }}$ ) and heavy-intensity or strenuous exercise $\left(>75 \% \dot{\mathrm{V}}_{2_{\max }}\right)$ on platelet reactivity have been extensively studied. Studies using conventional tests have measured agonist-induced platelet aggregation, release of markers of platelet activation, such as $\beta$-thromboglobulin, platelet factor 4 , and P-selectin, and an increase in metabolites such as thromboxane $\mathrm{B}_{2}$ after moderate-intensity exercise (21-24). Those studies failed to yield conclusive results regarding the effect of moderate-intensity exercise on platelet reactivity. 
Table 1. Classification of the intensity of an endurance exercise

\begin{tabular}{lccc}
\hline Classification of intensity & $\% \dot{\mathrm{VO}}_{2 \max }$ & \%HRmax & RPE scale \\
\hline Very light & $<30$ & $<35$ & $<10$ \\
Light & $30-49$ & $35-59$ & $10-11$ \\
Moderate & $50-74$ & $60-79$ & $12-13$ \\
Heavy & $75-84$ & $80-89$ & $14-16$ \\
Very heavy & $>85$ & $>90$ & $>16$ \\
\hline
\end{tabular}

$\mathrm{VO}_{2 \max }$, maximal volume of oxygen consumed per minute; HR, heart rate; RPE, Borg rating of perceived exertion. (Modified from Mahler DA, Froelicher VF, Miller NH, York TD. General principles of exercise prescription. In: ACSM's Guidelines for Exercise Testing and Prescription, 5th ed., 1995).

Heavy-intensity exercise $\left(>75 \% \dot{\mathrm{VO}}_{2_{\max }}\right)$ seems to enhance platelet reactivity.

\subsection{Effect of acute exercise on coagulation and fibrinolytic activity}

Moderate-intensity exercise is known to increase fibrinolytic activity without raising levels of coagulation activation markers, while heavy-intensity exercise concurrently activates both the fibrinolytic and coagulation system (25). Fibrinolytic activity is enhanced by exercise and the extent of that enhancement mainly depends on the intensity of exercise $(7,10,25-27)$. In healthy volunteers and patients with peripheral arterial disease, coronary artery disease, metabolic syndrome, or hypertension, moderate-intensity exercise consistently increased tissue plasminogen activator (t-PA) activity (28-33) but not plasminogen activator inhibitor-1 (PAI1) activity $(31,34)$. Heavy-intensity exercise seems to enhance fibrinolytic activity along with coagulation (25,35-37).

\subsection{Effect of long-term exercise on coagulation and fibrinolytic activity}

Antithrombotic effects of regular or long-term exercise have been measured in healthy volunteers and patients of various ages. Studies have found that long-term exercise inhibited thrombin generation, reduced platelet reactivity and fibrin formation, and increased fibrinolytic activity $(28,38-41)$. These results suggest that long-term exercise may help to prevent sudden death.

Because of individual variation, the thrombotic state of individuals needs to be measured before and during long-term exercise training. Since the thrombotic state is governed by a balance of and overall interaction between coagulation, fibrinolysis, platelet reactivity, and flow, the overall thrombotic state needs to be measured in individuals.

\section{Effects of exercise on the thrombotic state assessed using non-anticoagulated blood}

A wide variety of tests are used to measure the individual components of the hemostasis system, but
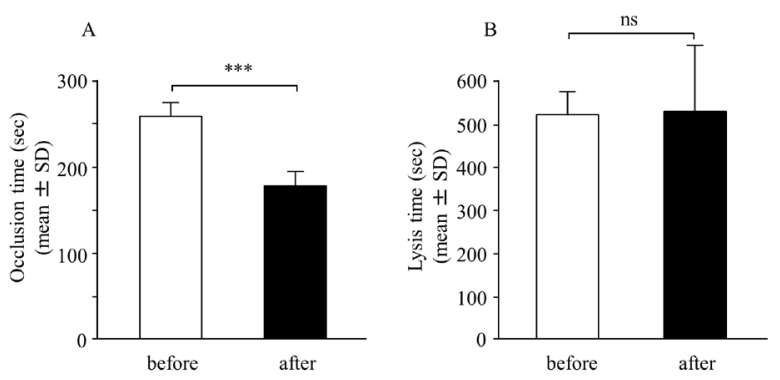

Figure 1. Effects of acute exercise on platelet reactivity (A) and fibrinolytic activity (B) as measured with a thrombotic status analyser. ${ }^{* * *} p<0.001$, ns: not significant. (Modified from Ikarugi et al. Thromb Res. 1997; 85:351-356).

their results are difficult to interpret. An overall test of hemostasis is greatly needed to assess the actual thrombotic state of an individual (12-14). Kovacs and her colleagues have focused on creating tests that can simultaneously measure platelet reactivity, coagulation, and endogenous thrombolytic (fibrinolytic) activity using one blood sample. Such a test, named the Global Thrombosis Test (GTT), is now commercially available. This test induces platelet-rich thrombus formation in non-anticoagulated (native) blood solely by shear forces, as opposed to conventional tests that use chemical agonists. Further, this test detects the spontaneous lysis of formed autologous thrombi in the same blood sample (15-20).

\subsection{Effect of acute exercise}

In a study by the current authors, results from a thrombotic status analyser indicated that low-intensity exercise $\left(50 \% \dot{\mathrm{VO}}_{2_{\max }}, 40 \mathrm{~min}\right)$ does not affect platelet reactivity (42). In contrast, moderate-intensity exercise $\left(60 \% \dot{\mathrm{VO}}_{2_{\max }}, 20 \mathrm{~min}\right)$ significantly increased platelet reactivity but did not affect fibrinolytic activity (Figure 1) (43).

In another study by the current authors, results from a haemostatometer verified that the effects of exercise at different levels of intensity on the thrombotic status depended on the individual's anaerobic threshold (AT), platelet reactivity, and coagulation not only during exercise but also during the recovery period after exercise (44). A significant increase in platelet reactivity (H1) and coagulation (CT1) was observed immediately and 


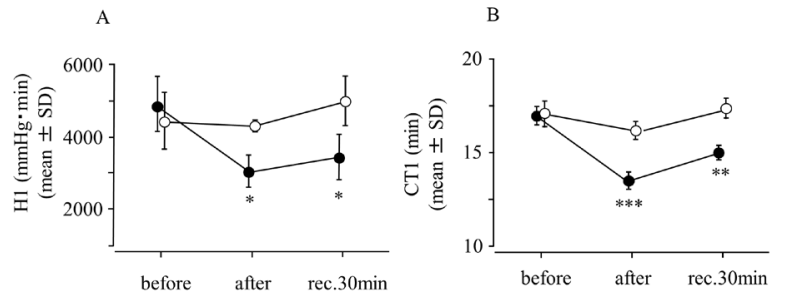

Figure 2. Effects of acute exercise on platelet reactivity (A: H1) and coagulation (B: CT1) as measured with a haemostatometer. Effects of low-intensity exercise (Ex-VT $90 \%$; approximately $55 \% \mathrm{VO}_{2 \max }, 30 \mathrm{~min}$ ) and high-intensity exercise (Ex-VT 130\%; approximately $80 \% \dot{\mathrm{VO}}_{2 \max }, 30 \mathrm{~min}$ ) on platelet reactivity and coagulation; O, Ex-VT 90\%; •, Ex-VT $130 \%$; ${ }^{*} p<0.05,{ }^{* *} p<0.01,{ }^{* * *} p<0.001$ vs. before. (Modified from Ikarugi et al. Pathophysiol Haemost and Thromb. 2003; 33:127-133).
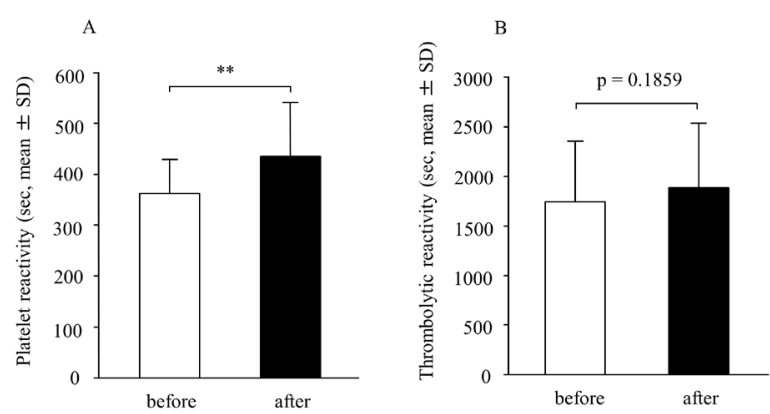

Figure 3. Effects of three months' exercise on platelet reactivity (A: OT) and endogenous fibrinolysis (B: LT) as measured with the Global Thrombosis Test. Effects in $n=$ 30 patients with metabolic syndrome; ${ }^{* *} p<0.01$. (Modified from Baba Y. Master's thesis, Kobe Gakuin University, 2012).

30 minutes after heavy-intensity exercise (corresponding to approximately $80 \% \dot{\mathrm{V}}_{2_{\max }}$ ), but such changes were not observed after moderate-intensity exercise (corresponding to approximately $55 \% \mathrm{~V}^{-} 2_{\text {max }}$ ) (Figure 2).

\subsection{Effect of long-term exercise}

Research used the GTT to measure the thrombotic state in patients with metabolic syndrome before and after three months' exercise (45). Results of that research are shown in Figure 3. A thrombotic state indicated by hyper-platelet reactivity before long-term exercise abated after exercise, but long-term exercise did not appear to affect endogenous fibrinolytic activity.

The thrombotic state was measured in healthy volunteers and patients under various conditions. The shear-induced thrombosis and thrombolysis tests were performed on non-anticoagulated blood (haemostatometer, thrombotic status analyser, and GTT). The thrombotic state was influenced by age (46), smoking (46-48), gender (47), and race (49). These findings corroborate the results of clinical studies indicating that physical exercise or sports helped to prevent a prothrombotic state and increased an individual's quality of life $(3,38,41,50)$.
In conclusion, using the GTT and a nonanticoagulated blood sample to measure the thrombotic state at rest and immediately after exercise may help to solve the exercise paradox.

\section{References}

1. Lavie CJ, Thomas RJ, Squires RW, Allison TG, Milani $\mathrm{RV}$. Exercise training and cardiac rehabilitation in primary and secondary prevention of coronary heart disease. Mayo Clin Proc. 2009; 84:373-383.

2. Shiroma EJ, Lee IM. Physical activity and cardiovascular health lessons learned from epidemiological studies across age, gender, and race/ethnicity. Circulation. 2010; 122:743-752.

3. Pollock ML, Franklin BA, Balady GJ, Chaitman BL, Fleg JL, Fletcher B, Limacher M, Pina IL, Stein RA, Williams M, Bazzarre T. Resistance exercise in individuals with and without cardiovascular disease: benefits, rationale, safety, and prescription: An advisory from the Committee on Exercise, Rehabilitation, and Prevention, Council on Clinical Cardiology, American Heart Association. Circulation. 2000; 101:828-833.

4. Albert CM, Mittleman MA, Chae CU, Lee IM, Hennekens CH, Manson JE. Triggering of sudden death from cardiac causes by vigorous exertion. N Engl J Med. 2000; 343:1355-1361.

5. Maron BJ. The paradox of exercise. N Engl J Med. 2000; 343:1409-1411.

6. Wang JS, Jen CJ, Kung HC, Lin LJ, Hsiue TR, Chen HI. Different effects of strenuous exercise and moderate exercise on platelet function in men. Circulation. 1994; 90:2877-2885.

7. El-Sayed MS, Sale C, Jones PG, Chester M. Blood hemostasis in exercise and training. Med Sci Sports Exerc. 2000; 32:918-925.

8. Thompson PD, Franklin BA, Balady GJ, et al. Exercise and acute cardiovascular events placing the risks into perspective: A scientific statement from the American Heart Association Council on Nutrition, Physical Activity, and Metabolism and the Council on Clinical Cardiology. Circulation. 2007; 115:2358-2368.

9. Thrall G, Lane D, Carroll D, Lip GY. A systematic review of the effects of acute psychological stress and physical activity on haemorheology, coagulation, fibrinolysis and platelet reactivity: Implications for the pathogenesis of acute coronary syndromes. Thromb Res. 2007; 120:819-847.

10. Posthuma JJ, van der Meijden PE, Ten Cate H, Spronk HM. Short- and Long-term exercise induced alterations in haemostasis: A review of the literature. Blood Rev. 2014; 29:171-178.

11. Mahler DA, Froelicher VF, Miller NH, York TD. General principles of exercise prescription. In: ACSM's Guidelines for Exercise Testing and Prescription, 5th ed. (Kenney WL, Humphrey RH, Bryant CX, eds.). Williams \& Wilkins, USA, 1995; pp. 153-176.

12. Harrison P. Platelet function analysis. Blood Rev. 2005; 19:111-123.

13. Paniccia R, Priora R, Liotta AA, Abbate R. Platelet function tests: A comparative review. Vasc Health Risk Manag. 2015; 11:133-148.

14. Gorog DA, Jeong YH. Platelet function tests: Why they 
fail to guide personalized antithrombotic medication. J Am Heart Assoc. 2015; 4:e002094.

15. Ratnatunga CP, Edmondson SF, Rees GM, Kovacs IB. High-dose aspirin inhibits shear-induced platelet reaction involving thrombin generation. Circulation. 1992; 85:1077-1082.

16. Gorog DA, Kovacs IB. Thrombotic status analyser: Measurement of platelet-rich thrombus formation and lysis in native blood. Thromb Haemost. 1995; 73:514520.

17. Yamamoto J, Yamashita T, Ikarugi H, Taka T, Hashimoto M, Ishii H, Watanabe S, Kovacs IB. Görög Thrombosis Test: A global in-vitro test of platelet function and thrombolysis. Blood Coagul Fibrinolysis. 2003; 14:3139 .

18. Yamamoto J, Inoue N, Otsui K, Ishii H, Gorog DA. Global Thrombosis Test (GTT) can detect major determinants of haemostasis including platelet reactivity, endogenous fibrinolytic and thrombin generating potential. Thromb Res. 2014; 133:919-926.

19. Okafor ON, Gorog DA. Review topic of the week. Endogenous fibrinolysis: An important mediator of thrombus formation and cardiovascular risk. J Am Coll Cardiol. 2015; 65:1683-1699.

20. Yamamoto J, Tamura Y, Ijiri Y, Iwasaki M, Murakami M, Matsuo O. Evaluation of antithrombotic effect: Importance of testing components and methodologies. Drug Discov Ther. 2015; 9:258-266.

21. Gonzales F, Mañas M, Seiquer I, Quiles J, Mataix FJ, Huertas JR, Martinez-Victoria E. Blood platelet function in healthy individuals of different ages. Effects of exercise and exercise conditioning. J Sports Med Phys Fitness. 1996; 36:112-116.

22. Kestin AS, Ellis PA, Barnard MR, Errichetti A, Rosner BA, Michelson AD. Effect of strenuous exercise on platelet activation state and reactivity. Circulation. 1993; 88:1502-1511.

23. Chicharro JL, Sanchez O, Bandes F, Guantes Y, Yges A, Lucia A, Legido JC. Platelet aggregability in relation to the anaerobic threshold. Thromb Res. 1994; 75:251-257.

24. Tokuue J, Hayashi J, Hata Y, Nakahara K, Ikeda Y. Enhanced platelet aggregability under high shear stress after treadmill exercise in patients with effort angina. Thromb Haemost. 1996; 75:833-837.

25. Weiss C, Seitel G, Bärtsch P. Coagulation and fibrinolysis after moderate and very heavy exercise in healthy male subjects. Med Sci Sports Exerc. 1998; 30:246-251.

26. Hansen JB, Wilsgård L, Olsen JO, Osterud B. Formation and persistence of procoagulant and fibrinolytic activities in circulation after strenuous physical exercise. Thromb Haemost. 1990; 64:385-389.

27. Womack CJ, Rasmussen JM, Vickers DG, Paton CM, Osmond PJ, Davis GL. Changes in fibrinolysis following exercise above and below lactate threshold. Thromb Res. 2006; 118:263-268.

28. Szymanski LM, Pate RR, Durstine JL. Effects of maximal exercise and venous occlusion on fibrinolytic activity in physically active and inactive men. J Appl Physiol. 1994; 77:2305-2310.

29. DeSouza CA, Dengel DR, Rogers MA, Cox K, Macko RF. Fibrinolytic responses to acute physical activity in older hypertensive men. J Appl Physiol. 1997; 82:17651770.

30. Womack CJ, Ivey FM, Gardner AW, Macko RF.
Fibrinolytic response to acute exercise in patients with peripheral arterial disease. Med Sci Sports Exerc. 2001; 33:214-219.

31. Morris PJ, Packianathan CI, Van Blerk CJ, Finer N. Moderate exercise and fibrinolytic potential in obese sedentary men with metabolic syndrome. Obes Res. 2003; 11:1333-1338.

32. Mustonen P, Lepantalo M, Lassila R. Physical exertion induces thrombin formation and fibrin degradation in patients with peripheral atherosclerosis. Arterioscler Thromb Vasc Biol. 1998; 18:244-249.

33. Rydzewski A, Sakata K, Kobayashi A, Yamazaki N, Urano T, Takada Y, Takada A. Changes in plasminogen activator inhibitor 1 and tissue-type plasminogen activator during exercise in patients with coronary artery disease. Haemostasis. 1990; 20:305-312.

34. Szymanski LM, Pate RR. Effect of exercise intensity, duration, and time of day on fibrinolytic activity in physically active men. Med Sci Sports Exerc. 1994; 26:1102-1108.

35. Ferguson EW, Bernier LL, Banta GR, Yu-Yahiro J, Schoomaker EB. Effects of exercise and conditioning on clotting and fibrinolytic activity in men. J Appl Physiol. 1987; 62:1416-1421.

36. Andrew M, Carter C, O'Brodovich H, Heigenhauser G. Increases in factor VIII complex and fibrinolytic activity are dependent on exercise intensity. J Appl Physiol. 1986; 60:1917-1922.

37. Davis GL, Abildgaard CF, Bernauer EM, Britton M. Fibrinolytic and hemostatic changes during and after maximal exercise in males. J Appl Physiol. 1976; 40:287-292.

38. Gram AS, Bladbjerg EM, Skov J, Ploug T, Sjödin A, Rosenkilde M, Madsen DE, Stallknecht BM. Three months of strictly controlled daily endurance exercise reduces thrombin generation and fibrinolytic risk markers in younger moderately overweight men. Eur J Appl Physiol. 2015; 115:1331-1338.

39. Wang JS, Li YS, Chen JC, Chen YW. Effects of exercise training and deconditioning on platelet aggregation induced by alternating shear stress in men. Arterioscler Thromb Vasc Biol. 2005; 25:454-460.

40. Schuit AJ, Schouten EG, Kluft C, de Maat M, Menheere PP, Kok FJ. Effect of strenuous exercise on fibrinogen and fibrinolysis in healthy elderly men and women. Thromb Haemost. 1997; 78:845-851.

41. Páramo JA, Olavide I, Barba J, Montes R, Panizo C, Muñoz MC, Rocha E. Long-term cardiac rehabilitation program favorably influences fibrinolysis and lipid concentrations in acute myocardial infarction. Haematologica. 1998; 83:519-524.

42. Ikarugi H, Shibata M, Ishii K, Yamamoto J. Shearinduced platelet reactivity in middle-aged women after low-intensity exercise. Thromb Res. 2001; 104:347-351.

43. Ikarugi H, Taka T, Nakajima S, Kato N, Ueda T, Matsumura K, Haga S, Yamamoto J. Detection of a prothrombotic state after acute aerobic exercise. Thromb Res. 1997; 85:351-356.

44. Ikarugi H, Shibata M, Shibata S, Ishii H, Taka T, Yamamoto J. High intensity exercise enhances platelet reactivity to shear stress and coagulation during and after exercise. Pathophysiol Haemost Thromb. 2003; 33:127133.

45. Baba Y. Effects of exercise and diet interventions modeled on Healthy Japan 21 on thrombus formation. 
Master's thesis, Kobe Gakuin University, 2012 (in Japanese).

46. Ikarugi H, Yamashita T, Aoki R, Ishii H, Kanki K, Yamamoto J. Impaired spontaneous thrombolytic activity in elderly and in habitual smokers, as measured by a new global thrombosis test. Blood Coagul Fibrinolysis. 2003; 14:781-784.

47. Suehiro A, Wakabayashi I, Yamashita T, Yamamoto J. Attenuation of spontaneous thrombolytic activity measured by the global thrombosis test in male habitual smokers. J Thromb Thrombolysis. 2014; 37:414-418.

48. Yamashita T, Sato A, Ikarugi H, Inoue A, Kitamori K, Ishii H, Yamamoto J. Significantly reduced spontaneous thrombolytic activity in older men: A possible explanation for the gender differences in risk of acute coronary syndromes. Thromb Res. 2005; 116:127-131.

49. Gorog DA, Yamamoto J, Saraf S, Ishii H, Ijiri Y, Ikarugi H, Wellsted DM, Mori M, Yamori Y. First direct comparison of platelet reactivity and thrombolytic status between Japanese and Western volunteers: Possible relationship to the "Japanese paradox". Int J Cardiol. 2011; 152:43-48.

50. von Mackensen S, Harrington C, Tuddenham E, Littley A, Will A, Fareh M, Hay CR, Khair K. The impact of sport on health status, psychological well-being and physical performance of adults with haemophilia. Haemophilia. 2016; 22:521-530.

(Received December 5, 2016; Revised January 28, 2017; Accepted January 30, 2017) 